\title{
Value of real-time tissue elastography for squamous cell carcinoma of the tongue
}

\author{
Dilruba Aktar, Hirofumi Tomioka, Hideaki Hirai, Yu Oikawa, Yumi Mochizuki, Hiroaki Shimamoto and Hiroyuki Harada* \\ Oral and Maxillofacial Surgery, Department of Oral Health Sciences, Graduate School of Medical and Dental Sciences, Tokyo Medical and Dental University, 1-5- \\ 45 Yushima, Bunkyo-ku, Tokyo 113-8549, Japan
}

\begin{abstract}
Objectives: Real-time tissue elastography is an ultrasound tomography technique that can objectively display tissue elasticity. The aim of this study was to evaluate the strain ratio of tongue carcinoma and the normal tongue and to investigate how clinico-pathological factors influenced the strain ratio. We also investigated differences in the strain ratio between tumor and non-tumor tissue after preoperative chemo-radiotherapy.
\end{abstract}

Materials and methods: Patients with tongue carcinoma were categorized into two groups: 38 patients who underwent surgery alone and who underwent preoperative elastography (group 1), and 12 patients who underwent elastography before and after preoperative chemo-radiotherapy (group 2).

Results: The mean strain ratios in group 1 were $0.16 \pm 0.13$ in tumor tissue and $0.82 \pm 0.35$ in normal tissue. Statistical analysis revealed that the strain ratio of tumor significantly correlated with tumor thickness. In group 2 , the mean strain ratio of tumor tissue, scar tissue, and normal tissue were $0.19 \pm 0.18,0.51 \pm 0.28$, and $0.77 \pm$ 0.58 , respectively. The mean strain ratio of scar tissue was 0.51 and had lower elasticity than tumor tissue and higher elasticity than normal tissue.

Conclusions: It was useful to characterize the tissue distortion using the strain ratio. Additional studies to establish a cutoff value for tumor tissue might help expand the indications for limited surgery.

\section{Introduction}

Preservation of function is important to preserve quality of life for patients undergoing treatment for oral cancer. The tongue is an essential organ for speech, food bolus formation and deglutition. Alternatively, this site is a good candidate for organ preservation techniques with the goal of preserving speech and swallowing function. Fortunately, preoperative chemo-radiotherapy has enabled many patients to avoid surgery and to improve cancer control with few side effects for patients with large unresectable cancers. These combined (chemo-radiotherapy) modality treatments lead to higher cure rates while maintaining the patient's quality of life $[1,2]$. Indeed, advances in anticancer agent and radiotherapy have resulted in a potent antitumor effect in many patients. However, some patients treated with this strategy develop induration in the center of their tumor that histologically varies from viable tumor to scar tissue. If a determination could be made as to whether the remaining induration is tumor or scar tissue, it may be possible to establish criteria for limited resection versus no surgery [3-5].

Many diseases cause changes in the mechanical properties of tissues. The tissue flexibility is decreased by pathologic tissue changes, such as inflammation and tumor growth. Indeed cancer growth results in an increase in tissue stiffness, even during the early stages of cancer. Real-time tissue elastography is an ultrasound tomography modality that can objectively display tissue elasticity [6]. Basic principles including calculated method of strain ratio had been well described in the literature accompanied with a new guideline [7]. The strain distributions in tissues in response to external compression are closely related to the distribution of tissue elasticity. These strain images can give a clear illustration of underlying tissue stiffness and provides useful clinical information. Erastography is currently under investigation for diagnosing malignant breast tumor, thyroid tumor and cervical lymph node metastases [8,9]. However, there are no reports of its use in the evaluation of primary oral cancers. This method relies of the phenomenon in which compression of living tissue results in marked distortion of flexible tissues without affecting the shape of stiff tissues. When applying different levels of compression or relaxation, the elasticity imaging algorithm measures the displacement and strain by analyzing the RF (radiofrequency) signal in real time with subsequent conversion to a color-coded image. Using this method, the elasticity and strain ratio of squamous cell carcinoma of the tongue was measured, and the elasticity and strain ratio of the scar portion was quantified in cases in which preoperative therapy was performed [10].

\section{Materials and methods}

\section{Eligibility criteria}

The study was conducted between August 2011 and April 2015 in the Department of Oral and Maxillofacial Surgery of the Tokyo Medical and Dental University, Japan. All study protocols were approved by the institutional ethics committee (Approval number 729). All patients

Correspondence to: Hiroyuki Harada, Professor, Oral and Maxillofacial Surgery, Department of Oral Health Sciences, Graduate School of Medical and Dental Sciences, Tokyo Medical and Dental University, 1-5-45 Yushima, Bunkyo-ku, Tokyo 113-8549, Japan, Tel: +81-3-5803-5508, Fax: +81-3-5803-0199, E-mail: hiro-harada.osur@tmd.ac.jp

Received: October 27, 2016; Accepted: November 04, 2016; Published: November 07, 2016 
provided written informed consent before entry into this study. The subjects comprised 50 patients ( 38 men, 12 women; mean age, 59.1 years; age range, 30-86 years) who were treated for squamous cell carcinoma of tongue.

Patients were categorized into two groups. Group 1 included 38 patients. These patients underwent surgery alone and elastography before glossectomy. Patients in group 1 underwent surgery for partial glossectomy $(n=14)$ or for hemi-glossectomy $(n=24)$. Group 2 included 12 patients who underwent elastography before and after preoperative chemo-radiotherapy. Patients in group 2 underwent surgery for hemiglossectomy $(n=7)$ or for subtotal glossectomy $(n=5)$. Preoperative therapies were chemoradiotherapy in 5 patients and chemotherapy in 7 patients. Preoperative chemoradiotherapy consisted of a total dose of S-1 at $65 \mathrm{mg} / \mathrm{m}^{2}$ per day for 5 consecutive days over 4 consecutive weeks with concomitant radiotherapy ( $40 \mathrm{~Gy}$, provided at a fractional dose of 2 Gy for 5 days/week) in 4 patients. Preoperative chemotherapy consisted of a regimen of CDDP $80 \mathrm{mg} / \mathrm{m}^{2}$ (day 1) and 5-FU $800 \mathrm{mg} /$ $\mathrm{m}^{2}$ per day (days 1-5) plus a regimen of CDDP $60 \mathrm{mg} / \mathrm{m}^{2}$ and docetaxel $60 \mathrm{mg} / \mathrm{m}^{2}$ (day 1) and 5 -FU $600 \mathrm{mg} / \mathrm{m}^{2}$ per day (days 1-5) for each one course plus 40 Gy of radiotherapy in one patient. Preoperative chemotherapy consisted of a regimen of CDDP $80 \mathrm{mg} / \mathrm{m}^{2}$ (day 1) and 5 -FU $800 \mathrm{mg} / \mathrm{m}^{2}$ per day (days 1-5) for one course in 2 patient and for 2 courses in 2 patients. Preoperative chemotherapy consisted of a regimen of CDDP $60 \mathrm{mg} / \mathrm{m}^{2}$ and docetaxel $60 \mathrm{mg} / \mathrm{m}^{2}$ (day 1) and 5-FU $600 \mathrm{mg} / \mathrm{m}^{2}$ per day (days 1-5) for one course in one patient and for 2 courses in 2 patients. The median interval between end of preoperative treatment was 22.5 days (range, 13-35 days). T classification (group 1/ group 2) was T1: 6/0, T2: 26/4, T3: 6/8, and the N classification was N0: 30/3, N1: 4/1, N2b: 4/3 and N2c: 0/5.

\section{Histological classification of malignancy}

In group 1 , the histological classification of malignancy was evaluated according to the multifactorial system proposed by Anneroth (Table 1) [11]. The histologic malignant score was determined using blocks of tissue that showed the maximum cross-sectional area. The number of mitoses was assessed by evaluating five random fields (magnification $\mathrm{x} 400$ ).

\section{Elastography}

An Avious ultrasound system (HITACHI, Japan) was used to evaluate elasticity. Measurements were taken by an operator over 20 years of experience in head and neck ultrasonography. Ultrasonographic features of each tumor including margins,

Table 1.Histologic malignancy grading system.

Morphologic parameter

\begin{tabular}{|l|l|}
\hline Degree of keratinization & $\begin{array}{l}\text { Highly keratinized } \\
(>50 \% \text { of the cells })\end{array}$ \\
\hline Nuclear polymorphism & $\begin{array}{l}\text { Little nuclear polymorphism }(>75 \% \\
\text { mature cell })\end{array}$ \\
\hline
\end{tabular}

\begin{tabular}{|l|l|l|}
\hline Number of mitotic cells & $0-1$
\end{tabular}

(A) Histologic grading of malignancy of tumor cell population point.

\begin{tabular}{|c|c|c|c|c|}
\hline Morphologic parameter & $\mathbf{I}$ & II & III & VI \\
\hline Pattern of invasion & $\begin{array}{l}\text { Pushing, well delineated infiltrating } \\
\text { borders }\end{array}$ & $\begin{array}{l}\text { Infiltrating, solid cords, bands and / } \\
\text { or strands. }\end{array}$ & $\begin{array}{l}\text { Small groups or cords of infiltrating } \\
\text { cells }(n>15)\end{array}$ & $\begin{array}{l}\text { Marked and wide spread cellular } \\
\text { dissociation in small group of cells } \\
(\mathrm{n}>15) \text { and/or single cells }\end{array}$ \\
\hline Stage of invasion (depth) & $\begin{array}{l}\text { Carcinoma in situ and/or } \\
\text { questionable invasion }\end{array}$ & $\begin{array}{l}\text { Distinct invasion, but involving } \\
\text { lamina propria only }\end{array}$ & $\begin{array}{l}\text { Invasion below lamina propria } \\
\text { adjacent to muscles, salivary gland } \\
\text { tissue and periosteum }\end{array}$ & $\begin{array}{l}\text { Extensive and deep invasion } \\
\text { replacing most of the stromal tissue } \\
\text { and infiltrating jaw bone }\end{array}$ \\
\hline Lympho-plasmocytic infiltration & Marked & Moderate & Slight none & None \\
\hline
\end{tabular}

(B) Histologic grading of malignancy of tumor cell population point.

echogenicity, ultrasound transmission and color Doppler signal were evaluated. Endosonography was performed to examine the tongue lesion, and $2 \%$ xylocaine jelly (a water-based gel with $2 \%$ lidocaine hydrochloride) was used to couple the ultrasound between the probe and tongue lesion. Then, the probe was repeatedly applied to apply and release pressure (approximately $250 \mathrm{~g}$ ) to obtain an elastographic image (elastogram). The scanning plane was designed to move horizontally to show the maximum cross-sectional area across the tongue carcinoma. The system calculates the levels of resulting tissue deformation and display them as a color coded (red, green, blue) bar (feedback bar) on the side of the image. The bar displays the tissue deformation in real time. The "dual" display mode allows one to visualize the elastosonography image and the corresponding B mode image simultaneously on the monitor. In group 1, the strain ratio of the tumor and normal tissue was measured with the ROI (region of interest) set in tumor tissue and normal tissue on the maximum cross-sectional line. In group 2, the ROI was set in the tumor tissue and normal tissue, and the strain ratio was measured before preoperative therapy. After preoperative therapy, the ROI was set in the tumor tissue, normal tissue, and scar tissue on the maximum cross-sectional line, and the strain ratio of them was measured (Figure 1). As shown in the Figure 1, comparing before and after preoperative therapy, and the ROI was set in the tumor reduced area after preoperative therapy, which was defined as a scar. This strain elastography displays tissue stiffness in a continuum of colors from

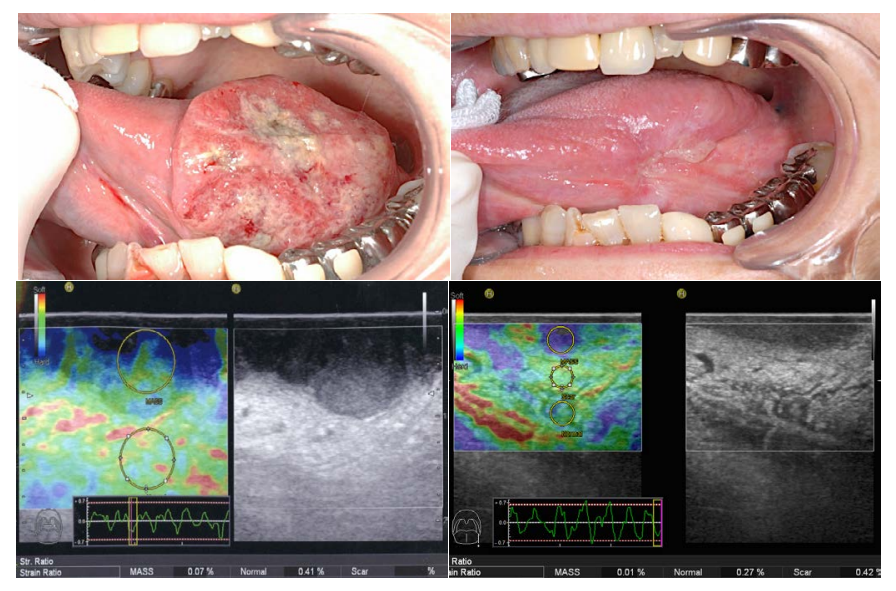

A: Initial examination

B: After two course of PF

Figure 1. Intraoral photograph and elastography image of the left side of the patients with T2 tougue carcinoma. A: Initial examination photograph and images. The ROI was set in the tumor tissue (describing 'MASS' in the image) and normal tissue, and the strain ratio was $0.07 \%$ and $0.41 \%$, respectively. B: Tumor thickness is reduced from $11.0 \mathrm{~mm}$ to 3.9 $\mathrm{mm}$ with two course of PF (Cisplatin and 5-Fluorouracil) therapy.The strain ratio of the tumor tissue, scar tissue, and normal tissue was $0.01 \%, 0.27 \%$, and $0.42 \%$, respectively.

\begin{tabular}{|l|l|l|} 
II & III & VI
\end{tabular}

Moderately keratinized (20-50\% of $\quad$ Minimal keratinization (5-20\% of $\quad$ No keratinization the cells) the cells)

\begin{tabular}{|l|l|l}
\hline Moderately abundant nuclear & Abundant nuclear polymorphism & Extreme nuclear polymorphism (0-
\end{tabular} \begin{tabular}{l|l|l} 
polymorphism $(50-75 \%$ mature cells $)$ & $(25-50 \%$ mature cells $)$ & $25 \%$ mature cells $)$
\end{tabular} \begin{tabular}{l|l|l}
$2-3$ & $4-5$ & $>5$
\end{tabular} 
red to green to blue, designating soft (high strain), intermediate (equal strain), and hard (no strain), respectively.

\section{Statistical analysis}

The statistical correlation between US thickness and histological thickness of tumor were analyzed using Pearson's correlation coefficient. Tumor thickness and the strain ratio were analyzed using the Mann-Whitney $U$ test. To identify correlative factors for strain ratio, data of histological parameters and strain ratios were analyzed by multiple regression analysis using SPSS data processing software (version 16.0).

\section{Results}

Figures 2 and 3 showed the correlation between histological

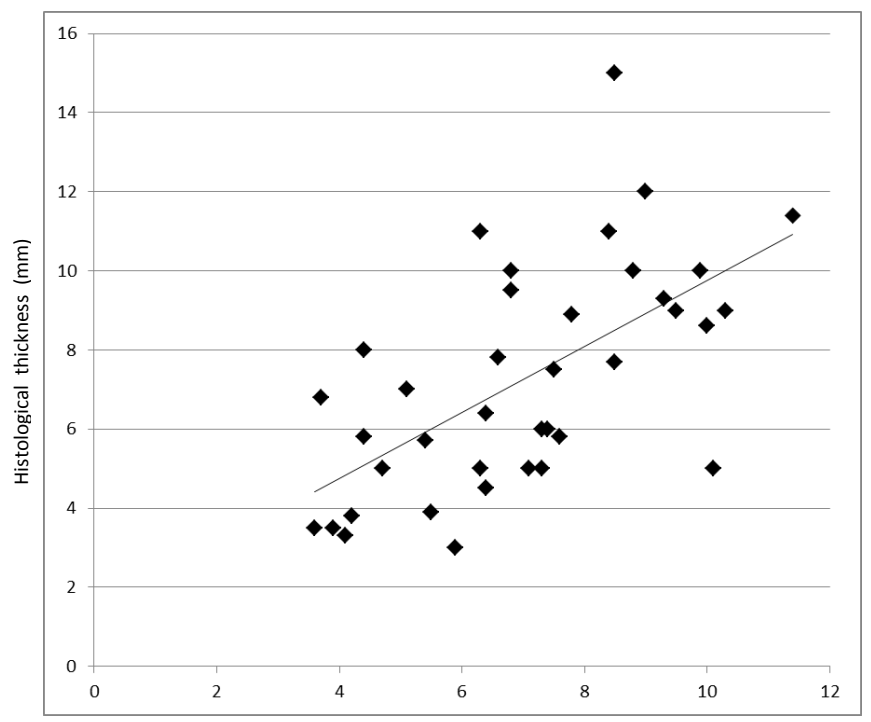

US thickness $(\mathrm{mm})$

Figure 2. Correlation between US thickness and pathological thickness in group 1 patients $(n=38)$. There is strong correlation between two groups $(r=0.749$, and $\mathrm{p}<0.001)$.

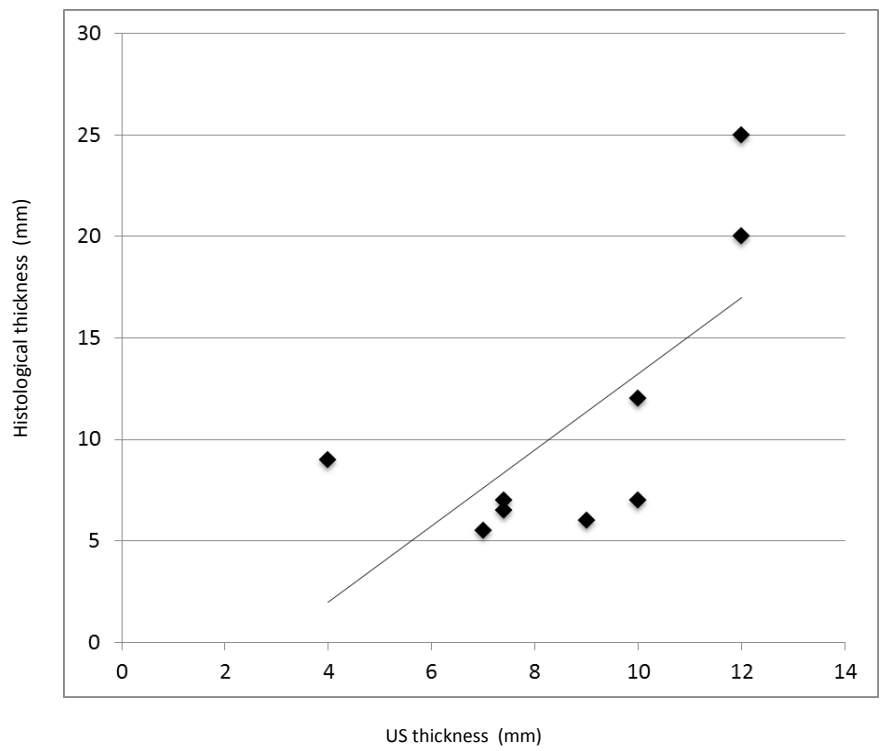

Figure 3. Correlation between US thickness and pathological thickness in group 2.There is modestly correlation between two groups $(\mathrm{r}=0.041$ and $\mathrm{p}=0.917)$. thickness and US thickness. Pearson correlation analysis using data from group 1 showed that histological thickness was positively correlated with US thickness $(\mathrm{r}=0.749 ; \mathrm{p}<0.001)$. In group 2, because only no viable tumor cells were seen in 3 cases, we evaluated histological thickness in 9 cases which viable tumor cells were present. Histological thickness was modestly correlated with US thickness ( $r=0.041$; $\mathrm{p}=0.917)$.

In group $1(\mathrm{n}=38)$, the strain ratio was $0.16 \pm 0.13$ for tumor tissue and $0.82 \pm 0.35$ for normal tissue (Figure 4 ). In group 2, the strain ratio of tumor tissue, scar tissue, and normal tissues was $0.19 \pm 0.18,0.51 \pm$ 0.28 , and $0.77 \pm 0.57$, respectively (Figure 4 ). The portion of primary tumor which decreased after introduced of chemo radiation therapy was defined as "scar". The scar tissue (yellow bar) showed strain that was intermediate between those of the normal and tumor tissue.

When the cutoff value for the strain ratio of tumor tissue was set 0.16 , there was a significant correlation between strain ratio and US tumor thickness ( $\mathrm{p}=0.044$ by the Mann-Whitney U test).

To identify predictive factors for strain ratio, the pathological findings of these patients were investigated. After collecting data regarding histological parameters and strain ratio, the data were analyzed by multiple regression analysis using SPSS data processing software. Analysis revealed that the strain ratio had a weaker correlation with histological tumor thickness and other histological parameters than US tumor thickness (Table 2).

\section{Discussion}

Imaging modalities, such as CT and MRI are useful for staging of disease and to assess tumor characteristics. However, these modalities are expensive and time consuming. US can precisely detect small changes in soft tissue. It is noninvasive, does not exposure the patient to radiation, easily allows serial examinations, is readily available in an outpatient office facility, and is less expensive when compared with other diagnostic tools. For the head and neck region, US is used to characterize the primary lesion and cervical lymph node in the preoperative and follow-up periods. Recently, several investigations have evaluated the efficacy of US for oral cancer, especially for measurement of tumor thickness [12,13]. In addition, US can be used to determine a sufficient surgical margin, intraoperatively [8]. The operator is able to select the most useful section for diagnosis. Therefore, sufficient skill and experience is required to acquire good quality images and to make accurate diagnoses.

The present study is the first to describe the efficacy of elastography for the characterization of tongue carcinoma. Tissue stiffness increases with cancer progression, even in the early stages of cancer. Indeed, studies have shown that breast and prostate cancers are stiffer than
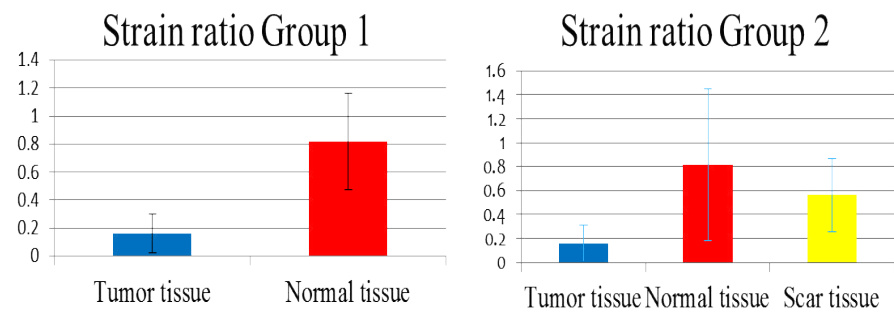

Figure 4. Strain ratios in each group (in the graph the bar in red, blue and yellow color represents normal or soft tissue, tumor or hard tissue, scar or intermediate tissue, respectively). 
Table 2. Multiple regression analysis.

\begin{tabular}{|c|c|c|c|c|c|c|c|}
\hline \multirow[t]{2}{*}{ Model } & \multicolumn{2}{|c|}{ Unstandardized Coefficients } & \multirow{2}{*}{$\begin{array}{c}\text { Standardized } \\
\text { Coefficients } \\
\text { Beta }\end{array}$} & \multirow[t]{2}{*}{ t } & \multirow[t]{2}{*}{ Sig. } & \multicolumn{2}{|c|}{$\mathbf{9 5 \%}$ Confidence Interval for B } \\
\hline & B & Std. Error & & & & Lower Bound & Upper Bound \\
\hline (Constant) & .855 & .470 & & 1.820 & .079 & -.107 & 1.817 \\
\hline Sex & -.006 & .066 & -.019 & -.096 & .924 & -.142 & .130 \\
\hline Age & -.002 & .002 & -.234 & -1.242 & .224 & -.006 & .001 \\
\hline Degree of Keratinization & -.078 & .111 & -.405 & -.699 & .490 & -.305 & .150 \\
\hline Nuclear Polymorphism & .121 & .112 & .628 & 1.075 & .292 & -.109 & .350 \\
\hline Mitotic cells & -.013 & .060 & -.059 & -.212 & .834 & -.136 & .111 \\
\hline Pattern of invasion & .042 & .067 & .161 & .625 & .537 & -.095 & .179 \\
\hline Stage of invasion & -.208 & .164 & -.246 & -1.264 & .217 & -.544 & .129 \\
\hline Lymph-plasmacyte & -.051 & .049 & -.222 & -1.054 & .301 & -.151 & .048 \\
\hline Histological thickness & -.003 & .009 & -.061 & -.314 & .756 & -.022 & .016 \\
\hline
\end{tabular}

normal tissue [14]. Real-time tissue elastography is a new ultrasound tomography technique that can objectively display tissue elasticity from which images of tissue stiffness can be depicted. In elastography, the tumor is repeatedly compressed and released via the probe, and arithmetic processing of the strain is translated into a color image. This technique has been used to distinguish between benign and malignant lesions in the breast, thyroid, prostate, and other tissues. Benign and malignant lesion in breast tissue can be differentiated with the ratio of strain in subcutaneous fat tissue to lesion (fat lesion ratio), using 4.0 as a cutoff value. In general, lower strain ratios indicate stiff tissue, while higher strain ratios indicate soft tissue [9].

The present study used quantitative strain elastography as a technique to investigate the relative stiffness of tongue lesions. In quantitative strain elastography, images are produced by the estimation of the tissue recovery response to the pressure induced on the tissue. The ratio of displacement (strain) of the normal tissue and in response to the induced pressure is defined as the strain index value. The stiffness of the lesion is compared by strain index values. A higher strain ratio corresponds to lower elasticity. The mean strain ratios of tumor tissue in squamous cell carcinoma of the tongue were nearly similar at 0.16 in group 1 and 0.19 in group 2 . Nearly similar values of 0.82 in group 1 and 0.77 in group 2 were seen in normal tissue as well. This is thought to support the reproducibility of this technique. Future studies should include a larger sample size to reduce the standard deviation. The mean strain ratio in scar tissue was 0.51 , showing lower elasticity than tumor tissue and higher elasticity than normal tissue. This result was expected and suggested that the portion of cancer tissue treated with preoperative chemo-radiotherapy contained lower elasticity than cancer tissue and higher elasticity than normal tissue. Although it could be caused by tumor cell density or lymphocyte infiltration, it is necessary to clear further study.

The histopathological analysis for strain ratio was correlated with tumor thickness significantly by univariate analysis, although the significant difference wasn't indicated by multivariate analysis. To elucidate the histopathological significance for strain ratio, we consider it necessary to analyze extracellular matrix such as collagen deposition or fibrosis of the tissue.

If a cutoff value for tumor tissue and scar tissue can be established, the possibility of limited surgery after chemo-radiotherapy can probably be expanded. Further, this tool could be used to assess for recurrent tumor during follow-up and to differentiate radiation ulcer from recurrent tumor.

\section{Conclusions}

In conclusion, the strain ratio determined on ultrasound elastography could be utilized as a noninvasive method for obtaining information regarding soft tissues. This technology will undoubtedly become an important tool for diagnosis and prognostic evaluations for tongue carcinoma. Because surgery remains an important treatment modality for tongue carcinoma, our goal is to preserve the function of the oral cavity. In future, larger prospective studies will be needed to establish a cutoff value for tumor tissue to expand the indication for limited surgery after preoperative treatment.

\section{Conflicts of interest}

The authors do not have any conflicts of interest.

\section{References}

1. Urba SG, Moon J, Shankar Giri PG, Adelstein DJ, Hanna E, et al. (2005) Organ preservation for advanced resectable cancer of the base of tongue and hypopharynx. A Southwest Oncology Group Trial. J Clin Oncol 23: 88-95.

2. Tschiesner U (2012) Preservation of organ function in head and neck cancer. GMS Curr Top Otorhinolaryngol Head Neck Surg 11: 07. [Crossref]

3. Robbins KT, Samant S, Vieira F, Kumar P (2004) Presurgical cytoreduction of oral cancer using intra-arterial cisplatin and limited concomitant radiation therapy (NeoRADPLAT). Arch Otolaryngol Head Neck Surg 130: 28-32. [Crossref]

4. Klug C, Berzaczy D, Voracek M, Millesi W (2008) Preoperative chemoradiotherapy in the management of oral cancer: a review. J Craniomaxillofac Surg 36: 75-88. [Crossref]

5. Kirita T, Ohgi K, Shimooka H, Yamanaka Y, Tatebayashi S, et al. (1999) Preoperative concurrent chemoradiotherapy plus radical surgery for advanced squamous cel carcinoma of the oral cavity: an analysis of long-term results. Oral Oncol 35: 597-606. [Crossref]

6. Onur MR, Poyraz AK, Ucak EE, Bozgeyik Z, Özercan IH, et al. (2012) Semiquantitative strain elastography of liver masses. J Ultrasound Med 31: 1061-1067. [Crossref]

7. Shiina T, Nightingale KR2, Palmeri ML2, Hall TJ3, Bamber JC4, et al. (2015) WFUMB guidelines and recommendations for clinical use of ultrasound elastography: Part 1: basic principles and terminology. Ultrasound Med Biol 41: 1126-1147. [Crossref]

8. Bhatia KS, Lee YY, Yuen EH, Ahuja AT (2013) Ultrasound elastography in the head and neck. Part I. Basic principles and practical aspects. Cancer Imaging 13: 253-259. [Crossref]

9. Zhou J, Zhou C, Zhan W, Jia X, Dong Y, et al. (2014) Elastography ultrasound for breast lesions: fat-to-lesion strain ratio vs gland-to-lesion strain ratio. Eur Radiol 24: 3171-3177. [Crossref]

10. Guazzaroni M, Spinelli A, Coco I, Del Giudice C, Girardi V, et al. (2014) Value of strain-ratio on thyroid real-time sonoelastography. Radiol Med 119: 149-155. [Crossref]

11. Anneroth G, Batsakis J, Luna M (1987) Review of the literature and a recommended system of malignancy grading in oral squamous cell carcinomas. Scand J Dent Res 95: 229-249. [Crossref]

12. Yuen AP, Ng RW, Lam PK, Ho A (2008) Preoperative measurement of tumor thickness 
of oral tongue carcinoma with intraoral ultrasonography. Head Neck 30: 230-234. [Crossref]

13. Shintani S, Nakayama B, Matsuura H, Hasegawa Y (1997) Intraoral ultrasonography is useful to evaluate tumor thickness in tongue carcinoma. Am J Surg 173: 345-347. [Crossref]

14. Krouskop TA, Wheeler TM, Kallel F, Garra BS, Hall T (1998) Elastic moduli of breast and prostate tissues under compression. Ultrason Imaging 20: 260-274. [Crossref]

Copyright: (O2016 Aktar, D. This is an open-access article distributed under the terms of the Creative Commons Attribution License, which permits unrestricted use, distribution, and reproduction in any medium, provided the original author and source are credited. 